\title{
The Bacterial Superoxide Dismutase and Glutathione Reductase Are Crucial for Endophytic Colonization of Rice Roots by Gluconacetobacter diazotrophicus PAL5
}

\author{
Sylvia Alquéres, ${ }^{1}$ Carlos Meneses, ${ }^{2}$ Luc Rouws, ${ }^{3}$ Michael Rothballer, ${ }^{1}$ Ivo Baldani, ${ }^{3}$ Michael Schmid, ${ }^{1}$ \\ and Anton Hartmann ${ }^{1}$ \\ ${ }^{1}$ Helmholtz Zentrum München, German Research Center for Environmental Health (GmbH), Research Unit Microbe-Plant \\ Interactions, Ingolstädter Landstrasse 1, D-85764 Neuherberg, Germany; ${ }^{2}$ Universidade Estadual da Paraíba, Centro de \\ Ciências Agrárias e Ambientais, Departamento de Agroecologia e Agropecuária/MCA, 58429-500, Campina Grande, PB, \\ Brazil; ${ }^{3}$ Laboratório de Genética e Bioquímica, Embrapa Agrobiologia, Rodovia BR 465, km 07, 23891-000, Seropédica, RJ, \\ Brazil
}

Submitted 7 December 2012. Accepted 19 April 2013.

\begin{abstract}
Gluconacetobacter diazotrophicus is an aerobic diazotrophic plant-growth-promoting bacterium isolated from different gramineous plants. We showed that reactive oxygen species (ROS) were produced at early stages of rice root colonization, a typical plant defense response against pathogens. The transcription of the pathogen-related-10 gene of the jasmonic acid (JA) pathway but not of the PR-1 gene of the salicylic acid pathway was activated by the endophytic colonization of rice roots by $G$. diazotrophicus strain PAL5. Quantitative polymerase chain reaction analyses showed that, at early stages of colonization, the bacteria upregulated the transcript levels of ROS-detoxifying genes such as superoxide dismutase (SOD) and glutathione reductase (GR). To proof the role of ROS-scavenging enzymes in the colonization and interaction process, transposon insertion mutants of the SOD and GR genes of strain PAL5 were constructed. The SOD and GR mutants were unable to efficiently colonize the roots, indicated by the decrease of tightly root-associated bacterial cell counts and endophytic colonization and by fluorescence in situ hybridization analysis. Interestingly, the mutants did not induce the PR-10 of the JA-pathway, probably due to the inability of endophytic colonization. Thus, ROS-scavenging enzymes of $G$. diazotrophicus strain PAL5 play an important role in the endophytic colonization of rice plants.
\end{abstract}

Plants interact with a wide range of microbial pathogens as well as with beneficial microbes. Because plants are sessile, they must rely on potent defense and immune systems that are able to differentiate between beneficial and pathogenic bacteria and to give the appropriate response to each challenge (Wojtaszek 1997). One of the most rapid plant defense reactions after pathogen attack is the so-called oxidative burst, which consists of the production of reactive oxygen species (ROS), primarily superoxide and $\mathrm{H}_{2} \mathrm{O}_{2}$, at the site of attempted invasion (Apostol et al. 1989). ROS are primarily generated by plasma membrane-localized NADPH oxidases (Doke et al.

Corresponding author: S. Alquéres; E-mail: campbell-alqueres@helmholtzmuenchen.de or salqueres@ gmail.com; Telephone: + 49-(0)89 3187-2852.

(C) 2013 The American Phytopathological Society
1996). The produced ROS directly attack the microbial cells and further activate plant defense responses, functioning as a second messenger in the induction of various plant defenserelated genes (Torres et al. 2006). An important part of the plant immune system relies on key molecules that are modulated by redox signals. The most important of those molecules are salicylic acid (SA), jasmonic acid (JA), and ethylene (ET) that regulate mutually antagonistic defense responses that are differentially effective against specific types of microbes. Defense against pathogens with a biotrophic lifestyle is generally triggered by SA-dependent responses, whereas necrotrophic pathogens and herbivorous insects are commonly deterred by JA/ET-dependent defenses (Koornneef et al. 2008). The JA response is also activated in the induced systemic resistance (ISR) response against nonpathogenic rhizobacteria (van Loon et al. 2008).

Although the accumulation of $\mathrm{H}_{2} \mathrm{O}_{2}$ is often associated with a characteristic plant early response following perception of pathogen avirulence signals (Lamb and Dixon 1997), it was also shown that, in the symbiotic interaction with rhizobia, bacteria are initially recognized as intruders but then prevent or overcome plant defense responses (Baron and Zambryski 1995; Santos et al. 2001). Accumulation of ROS following the inoculation of nodulating nitrogen-fixing bacteria Sinorhizobium meliloti has also been observed in Medicago sativa (alfalfa) (Santos et al. 2001). These studies indicate that the regulation of the redox state must also play a major role in the interaction of plants with beneficial microbes; however, few studies analyzed this effect in the interaction between endophytic bacteria and plants of the family Poaceae.

Unlike rhizobia, some endophytic bacteria usually colonize the intercellular spaces of the plant and do not form nodules, indicating that the mechanisms involved in plant-microbe recognition and establishment of the interaction might be profoundly different. Plant growth-promoting bacteria (PGPB) are one type of bacteria that confers beneficial effects to the plant, such as an increase in plant growth. Gluconacetobacter diazotrophicus is an endophytic diazotrophic PGPB found in high numbers in internal tissues of plants such as sugarcane (Cavalcante and Dobereiner 1988) and rice (Muthukumarasamy et al. 2005). Increase in plant growth is achieved as result of transferred fixed nitrogen, phytohormone production (Sevilla et al. 2001), phosphate and zinc solubilization (Saravanan et al. 2007), and control of phyto- 
pathogens (Blanco et al. 2005; Mehnaz and Lazarovits 2006). In 2009, the complete genome of $G$. diazotrophicus was published, bringing interesting insights about its endophytic lifestyle (Bertalan et al. 2009).

In a recent study, we demonstrated that the ROS-detoxifying genes of $G$. diazotrophicus PAL5 were coexpressed with the nif genes in laboratory growth cultures controlling ROS levels during oxygen-sensitive nitrogen-fixation activity (Alquéres et al. 2010). This raised the question of whether, during endophytic colonization of roots, genes for ROS detoxification were expressed. In this report, we focus on ROS production as a local plant defense event induced by $G$. diazotrophicus after the inoculation of rice roots as model plant (Meneses et al. 2011), and the bacterial strategies to counteract this challenge.

We demonstrate that, after inoculation of rice plants, there is an increase in ROS levels in the roots. Due to the toxicity of ROS molecules and their importance in plant defense responses, plants and plant pathogens have developed strategies for ROS detoxification (Molina and Kahmann 2007). Expression analysis showed that plant-colonizing bacteria increase the expression of ROS-detoxifying enzymes to cope with the plant-derived ROS. Insertional mutants for superoxide dismutase (SOD) and glutathione reductase (GR), two major ROS-detoxifying enzymes, had less endophytic colonization efficiency. We also analyzed the activity of key genes of the SA- and JA-dependent defense pathways in response to bacterial inoculation and showed that, whereas the G. diazotrophicus PAL5 wild type (WT) induces the JA-dependent pathway, the mutants were not able to trigger this defense system.

\section{RESULTS}

\section{Construction and properties of knockout mutants} for SOD and GR.

To evaluate the importance of particular ROS-detoxifying enzymes for the colonization process, we constructed insertion mutants of the genes encoding one GR $(g r:: T n 5)$ and the sole SOD $(\operatorname{sod}:: \operatorname{Tn} 5)$

Growth rates and capacity to form nitrogen fixing aerotactic pellicles were similar for the WT and the mutants; therefore, indicating that the interruption of the SOD or GR gene did not affect general growth features such as nitrogen fixation (Fig. 1A and B). When exposed to paraquat, a redox cycler that increases the generation of superoxide, in an agar diffusion test, a growth inhibition halo was observed for the mutants but not for the WT strain (Fig. 1C). When exposed to $\mathrm{H}_{2} \mathrm{O}_{2}$, the inhibition halos were approximately $20 \%$ bigger for both mutants compared with the WT (Fig. 1D). These data showed that the mutants were more sensitive to ROS. Knowing that ROS are produced in response to bacterial contact to roots and that the mutants were more sensitive to them, we wanted to evaluate the impact of these mutations on the ROS accumulation observed in inoculated roots.

\section{ROS levels during $\boldsymbol{G}$. diazotrophicus infection.}

To analyze the ROS levels in situ at early stages of an endophytic interaction, we inoculated rice roots with $G$. diazotrophicus and used the fluorescent probe dichlorofluorescein diacetate sensitive to ROS, to assess the amount of ROS produced after the infection. Although there was no ROS production detectable in uninoculated roots, inoculation of WT bacteria triggered the accumulation of ROS in two clear peaks. One transient peak occurred $10 \mathrm{~min}$ after the inoculation and a second peak, which was stronger and longer, between 10 and $24 \mathrm{~h}$ after the bacterial inoculation (hai) (Fig. $2 \mathrm{~A})$. These results indicate that this endophytic PGPB might be perceived as an intruder, causing the plant to increase the production of ROS in defense. However, after $48 \mathrm{~h}$, this ROS response was decreased (Fig. 2A). During the root colonization of SOD- and GR-mutants, the ROS levels were significantly increased in the time window from 1 to 7 hai compared with the WT (Fig. 2B).
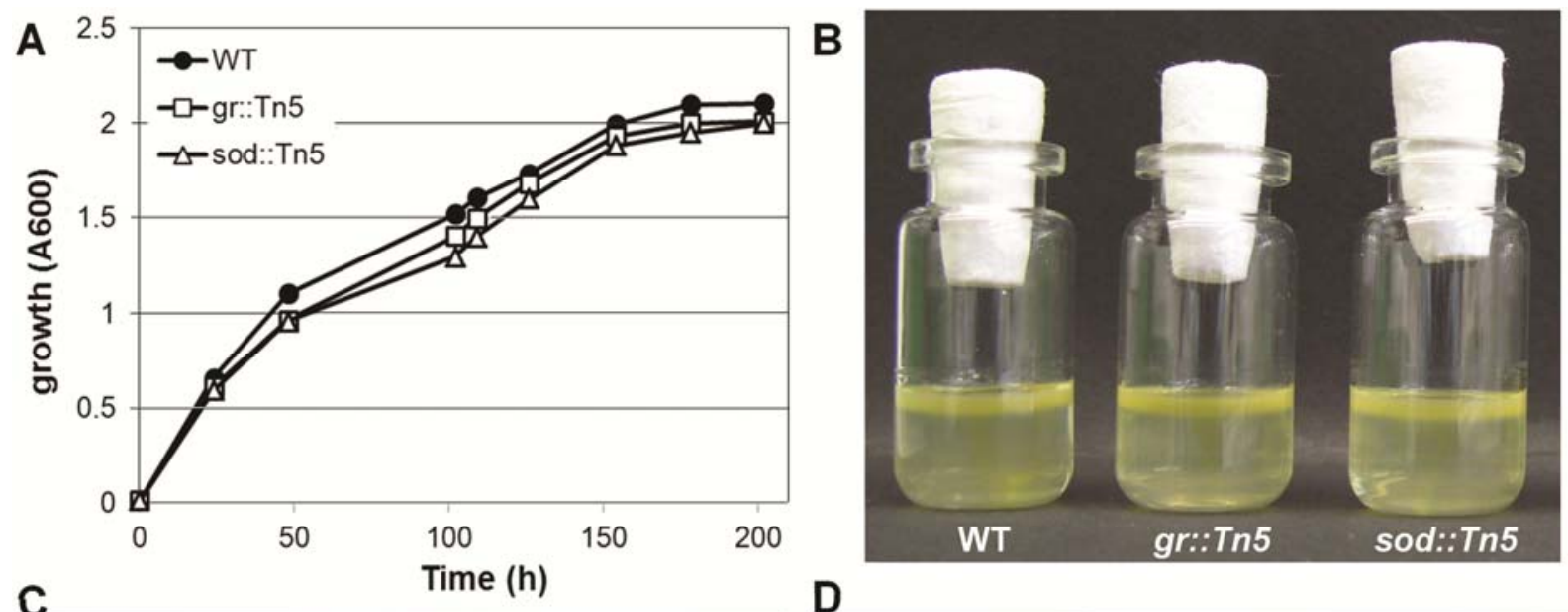

D
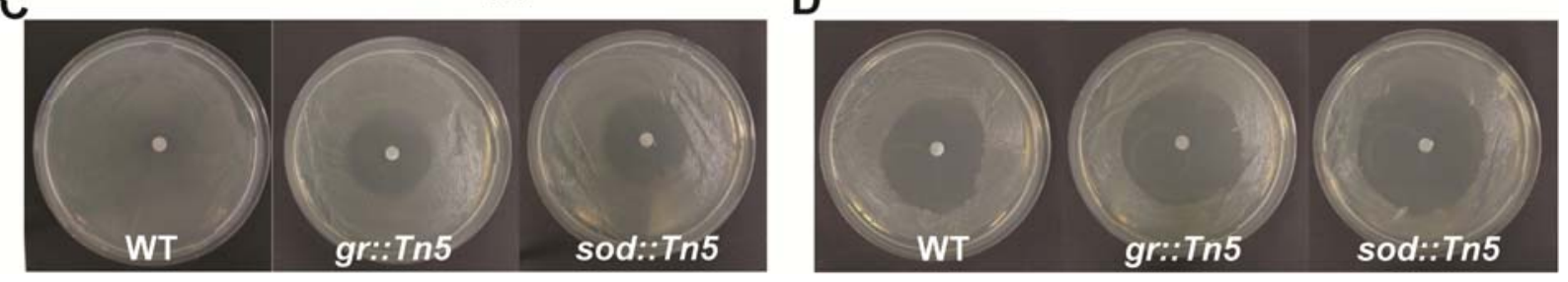

Fig. 1. Physiological characterization of the gr::Tn5 or sod::Tn5 mutants. A, Growth of wild-type (WT), gr::Tn5, and sod::Tn5 in liquid LGI-P medium (Reis et al. 1994) without nitrogen supplementation. B, Pellicle formation of WT, gr::Tn5, and sod::Tn5 in semisolid LGI-P medium without nitrogen supplementation. Pellicle formation is indicative of efficient nitrogen fixation and aerotactile abilities. Microorganisms grew at $30^{\circ} \mathrm{C}$ for 6 days. $\mathbf{C}$, Sensitivity of strains to Paraquat was assessed in an agar diffusion test in which a filter soaked with $5 \mu$ of Paraquat (10 mM) was placed on a DYGS agar plate seeded with the strains indicated. D, Sensitivity of strains to $\mathrm{H}_{2} \mathrm{O}_{2}$ was assessed in agar diffusion test in which a filter soaked with $5 \mu$ of $\mathrm{H}_{2} \mathrm{O}_{2}(35 \%$ [vol/vol]) was placed on a DYGS agar plate seeded with the strains indicated. 
In addition, it could be demonstrated that the nifD gene was expressed already in this early phase of colonization, indicating that the ROS-scavenging enzymes were sufficiently active to sustain biological nitrogen fixation during this phase (data not shown).

\section{Expression of bacterial ROS-detoxifying genes increases during infection process.}

We hypothesized that ROS-detoxifying enzymes from $G$. diazotrophicus should be activated to be able to cope with this redox challenge in the beginning of the infection process. To confirm that, we identified in the bacterial genome the presence of six classical ROS-detoxifying enzymes (one SOD [GDI_2168], two GR [GDI_2216 and GDI_2280], and three catalases [GDI_0079, GDI_0467, and GDI_2359]) and analyzed their expression profile by quantitative polymerase chain reaction (qPCR) at various times after the inoculation.

All enzymes analyzed showed an increase in the number of transcripts within the first few hours after inoculation (Fig. 3). The SOD presented an expression peak at 1 hai while the two GR and the catalases showed a peak between 1 and 7 hai. The similar expression profiles presented by the two ROS-detoxifying enzymes reinforced our hypothesis that the bacteria counteract a strong redox challenge in the initial steps of the infec-
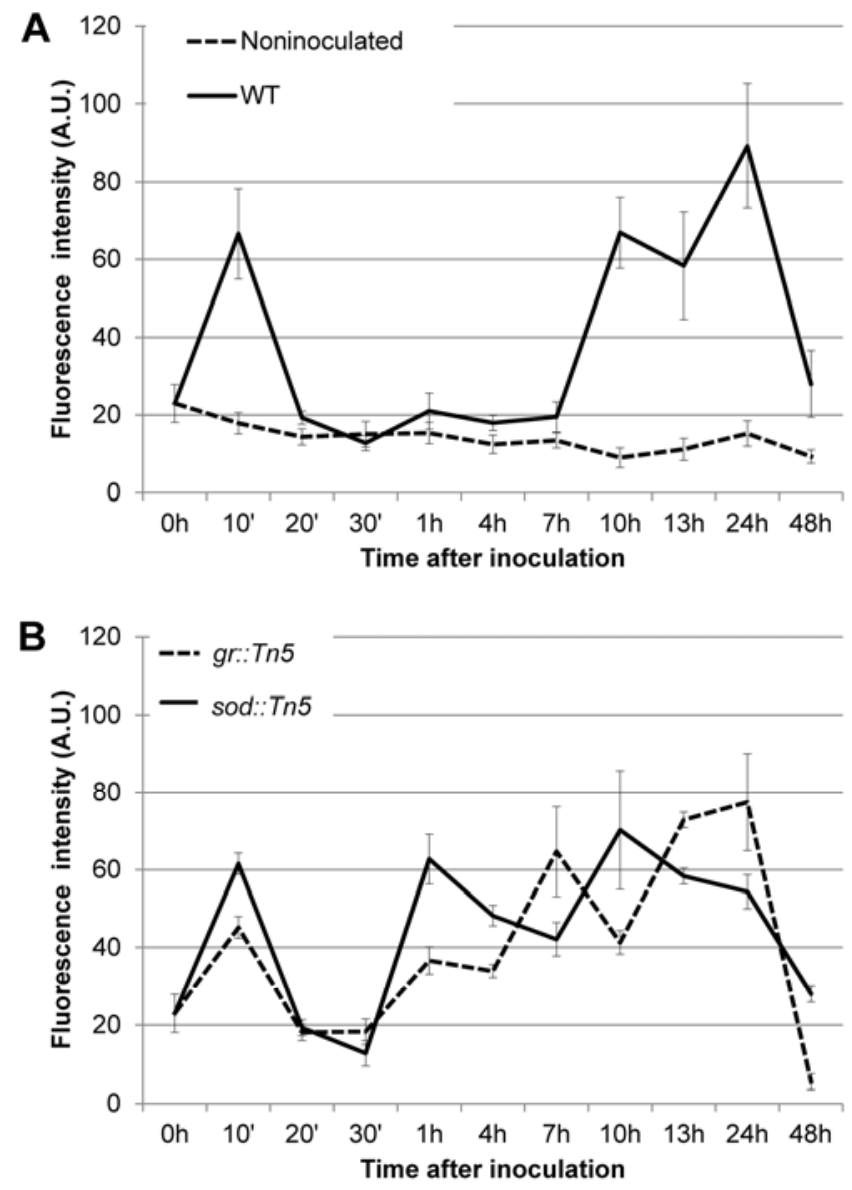

Fig. 2. Reactive oxygen species (ROS) production in rice roots induced by Gluconacetobacter diazotrophicus inoculation. A, Accumulation of ROS in noninoculated rice roots or in roots inoculated with $G$. diazotrophicus wild type (WT) $\mathbf{B}$, Accumulation of ROS in rice roots inoculated with gr::Tn5 or sod::Tn5. ROS amount was determined using the fluorescent probe $\mathrm{H}_{2}$ DCFDA. Fluorescence was expressed in relative arbitrary units (A.U.) Data presented are the average of quintuplicates \pm standard deviation (SD). Graph areas \pm SD: NI, $600 \pm 125$; WT, 2, $676 \pm 535 ; \Delta$ gr, 2,435 \pm 316 ; and $\Delta$ sod, $2,307 \pm 196$. tion by maintaining higher expression levels of the above enzymes, providing a mechanism that allows the bacteria to deactivate harmful ROS.

\section{Jasmonate pathway is induced during interaction.}

The accumulation of ROS after infection is also known to be a diffusible signal for induction of defense genes encoding enzymes involved in JA and SA pathways (Levine et al. 1994). We analyzed the expression of two plant genes known to function in SA- or JA-dependent pathways. Expression of pathogenrelated (PR)-1, a typical marker for an SA-mediated defense pathway (Qiu et al. 2007), and PR-10, marker for a JA-mediated
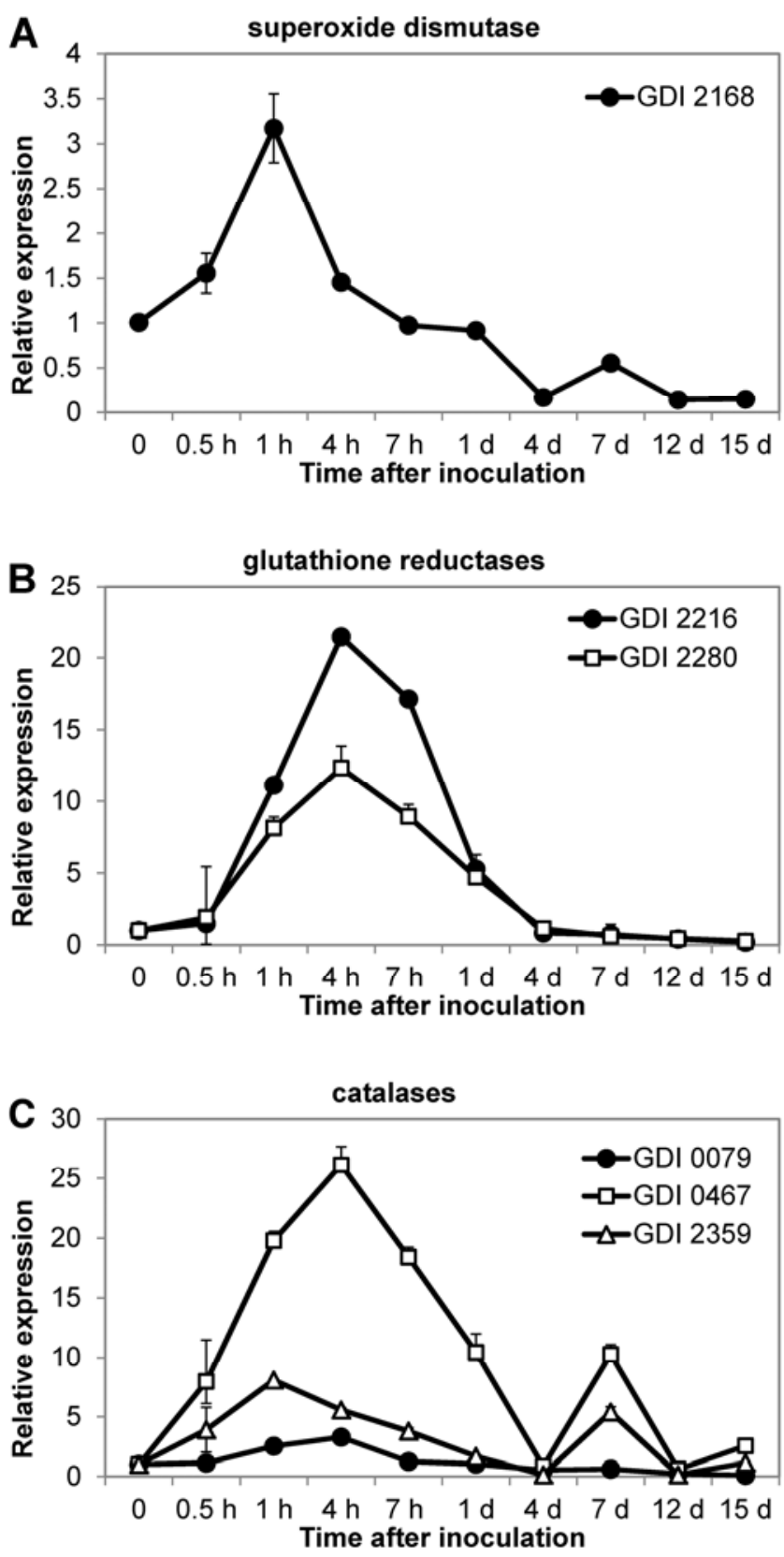

Fig. 3. mRNA expression of bacterial reactive oxygen species (ROS)-detoxifying genes at different times during the infection process. Data are expressed as the relative expression of the respective mRNAs compared with its expression on the time zero after inoculation. The 23S rRNA gene with a constitutive level of expression was used as the internal normalizer. A, Expression of the gene encoding the sole superoxide dismutase. B, Expression of the genes encoding for glutathione reductases. C, Expression of the genes encoding for catalases. Data are expressed as the average of three replicates \pm standard deviation. 
defense pathway (Miché et al. 2006), were monitored by qPCR. Our results showed that, although the PR-1 transcription was not observed at 24 hai, the inoculation of WT G. diazotrophicus PAL5 induced the transcription of the PR-10 gene, indicating that the JA pathway was active during this interaction (Fig. 4). There were no pathogenic symptoms observed on rice seedlings.

\section{Insertional mutants for SOD and GR}

have impaired endophytic colonization capacity.

To evaluate the impact of the mutations on colonization efficiency, we inoculated rice seedlings with WT or mutants of $G$. diazotrophicus PAL5 and quantified the bacterial colonization at 7 days after inoculation (dai). Root colonization was studied by two independent approaches. In the first approach, the number of CFU from plant roots and shoots without surface sterilization was obtained and compared with surface-sterilized roots and shoots to quantify the endophytic bacteria residing inside the plant as well as closely associated rhizoplane bacteria protected from the sterilizing agent by residing, for example, in surface folds or dents. In non-surface-sterilized plant parts, no difference was observed between the WT and the mutant strains (Fig. 5A). However, in surface-sterilized roots and

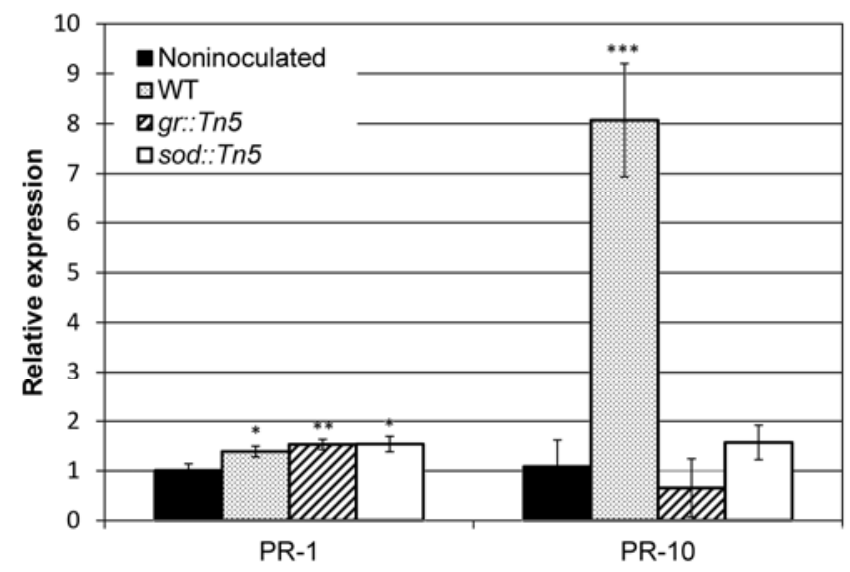

Fig. 4. Expression of plant defense genes at $24 \mathrm{~h}$ after bacterial inoculation. mRNA expression of pathogen-related (PR) genes compared with their expression on noninoculated control. Data are expressed as the relative expression of the respective mRNAs normalized to the endogenous control ubiquitin. PR-1 was used as a marker for the salicylic acid defense pathway and PR-10 for the jasmonic acid/ethylene defense pathway. Data are expressed as the average of three replicates \pm standard deviation. $P$ values were calculated using a $t$ test; $*, * *$, and $* * *$ indicate $P<0.05,0.01$, and 0.001 , respectively. Asterisks refer to comparison between the treated samples and the noninoculated control. shoots, a decrease by two orders of magnitude in CFU was observed in roots of plants inoculated with the $g r:: T n 5$ and sod::Tn5 mutants. No bacteria were isolated from the shoots of plants inoculated with the sod::Tn5 mutant (Fig. 5B). These results strongly indicate that GR and SOD are crucial enzymes for efficient plant association, especially endophytic colonization, but are not very important for epiphytic bacterial growth.

In a second approach, the spatial pattern of the bacterial colonization of roots by WT and mutant strains was investigated by fluorescence in situ hybridization (FISH) coupled with confocal laser-scanning microscopy (CLSM). Probes specific to $G$. diazotrophicus were labeled with Cy3. Representative pictures of roots are shown in Figure 6. Using this technique, a strong colonization of plant roots inoculated with WT bacteria was observed, whereas no or only a few bacterial cells were detected in roots inoculated with the mutants. These results reinforced our hypothesis that GR and SOD are critical enzymes for a successful intimate colonization.

The impaired colonization phenotype observed for the mutants indicates that they are either i) not able to survive the first initial ROS production and, therefore, unable to efficiently colonize the plant or ii) inducing a stronger defense response from the plant and, consequently, not able to colonize the plants. To ascertain that the phenotype observed was due to the lack of resistance from the bacteria to the initial redox challenge, we analyzed the expression of the PR-1 and PR-10 genes in plants inoculated with the mutants. Our results showed that, after the inoculation of both gr::Tn5 and sod::Tn5 mutants, the expression levels of those genes were not increased, indicating that the mutants were not able to further trigger a plant's defense response cascade (Fig. 4).

Taken together, our results demonstrate an accumulation of ROS during the first hours of endophytic colonization of rice roots by G. diazotrophicus PAL5. Thus, root-colonizing bacteria must be able to cope with that by activating their ROSdetoxification system. Mutants unable to detoxify ROS had impaired endophytic colonization efficiency.

\section{DISCUSSION}

The generation of ROS is known to be a characteristic early plant response following perception of pathogen signals (Apostol et al. 1989; Lamb and Dixon 1997). In 2001, ROS accumulation was even demonstrated after the inoculation of alfalfa with the symbiotic bacterium $S$. meliloti (Santos et al. 2001). Verhagen and associates (2010) also showed that inoculation of grapevine cell suspensions with Pseudomonas fluorescens and $P$. aeruginosa triggered a transient burst of $\mathrm{H}_{2} \mathrm{O}_{2}$.
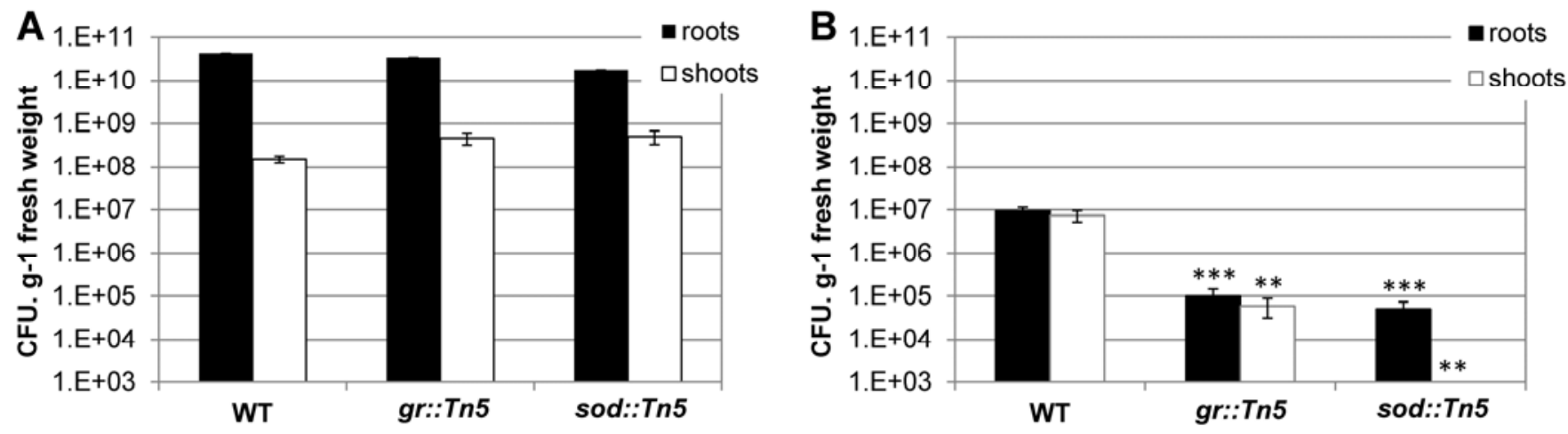

Fig. 5. Colonization of rice roots and shoots by wild-type (WT), gr::Tn5, and sod::Tn5. A, CFU obtained in rice roots and shoots at 10 days after inoculation (dai). B, CFU obtained from surface-sterilized rice roots and shoots at 10 dai. Experiments were done in biological triplicates. Data are expressed as the average of three replicates \pm standard deviation. $P$ values were calculated using a $t$ test: $*, * *$, and $* * *$ indicate $P<0.05,0.01$, and 0.001 , respectively. Asterisks refer to comparison between the samples inoculated with the mutants and samples inoculated with the WT. 
Recently, a study was published about the accumulation of ROS in plant cells cultures after the inoculation with the endophytic PGPB Burkholderia phytofirmans PsJN as compared with $P$. syringae (Bordiec et al. 2011). In that report, no significant accumulation of $\mathrm{H}_{2} \mathrm{O}_{2}$ was detected in the cell suspension medium after challenge with $B$. phytofirmans. To our knowledge, our report is the first showing the accumulation of ROS in roots triggered by the inoculation of a non-nodulating endophytic PGPB. The observation of ROS accumulation following the inoculation of a non-nodulating endophytic bacteria brings a new insight to this theme, because it was believed that the production of ROS following the inoculation of beneficial bacteria could be a response to the presence of a specific signal (nod factor) related to the nodulation process (Ramu et al. 2002) and not necessarily to the recognition of the bacteria as intruders.

It is known that $\mathrm{H}_{2} \mathrm{O}_{2}$ accumulation orchestrates plant disease-resistance mechanisms (Levine et al. 1994). The most studied and better understood resistance mechanism is the socalled systemic acquired resistance (SAR). In this response, pathogen recognition is followed by an increase in ROS levels that activates the production of SA that will eventually induce the expression of PR genes (Pieterse et al. 2009). The second most studied systemic resistance mechanism is the ISR, triggered by wounding from herbivory or necrosis-inducing plant pathogens. In this case, instead of SA, the main hormones mediating this response are JA and ET. The production of these hormones is often associated with the expression of another class of PR genes that are more effective against this type of pathogen (Pieterse et al. 2009). The third type of systemic resistance is described as rhizobacteria-ISR (RISR) and is induced by beneficial soilborne microorganisms and rhizobacteria. Like microbial pathogens, microbe-associated molecular patterns are recognized by the plant, resulting in a mild but effective activation of the immune response in systemic tissues (van Loon et al. 1998). In contrast to SA-dependent SAR, RISR is usually associated with priming for enhanced defense rather than direct activation of defense systems (Van Wees et al. 2008; Zamioudis and Pieterse 2012).

It has been suggested that generation of ROS is one of the earliest events in plant response involved in the development of RISR in plants (Torres et al. 2006; van Loon et al. 2008); therefore, we analyzed the expression of PR genes as markers of SA and JA/ET defense pathways. From this experiment, we could see an increase in PR-10, a marker for the JA/ETdefense pathway in rice plants. It can be speculated that $G$. diazotrophicus exerts a similar response in sugarcane plants, because sugarcane plants inoculated with $G$. diazotrophicus are more resistant to the infection of pathogens such as Xanthomonas albilineans, Colletotrichum falcatum, and Meloidogyne incognita. In addition, accumulation of an extracellular matrix around bacterial cells in the protoxylem and xylem parenchyma was observed by James and associates (2001). Furthermore, accumulation of polysaccharides and tannins in the parenchyma cells around the metaxylem of sugarcane inoculated with $G$. diazotrophicus has been reported by Dong and associates (1997), suggesting that the plant defense system is activated during the interaction with the bacterium. Although these observations were done in another plant system, our results suggest that these effects possibly could be due to the activation of the JA/ET-dependent pathway. In accordance with that, Nogueira and associates (2001) and Cavalcante and associates (2007) showed that the activity of some genes involved in the ET-signaling pathway was triggered in sugarcane plants after $G$. diazotrophicus inoculation. Rice plants inoculated with the mutants showed a reduced expression of PR-10 when compared with the WT (Fig. 4). This absence of response could be another indication that the mutants are not able to colonize the plants and trigger the PR-10 expression from the plant.

Another question raised by the accumulation of ROS during the bacterial invasion is which mechanisms $G$. diazotrophicus uses to counteract plant defense response. A recent study showed that the rice endophyte metagenome contained a high number and diversity of genes encoding enzymes involved in the detoxification of ROS, and the authors hypothesized that endophytes require these enzymes to be able to successfully colonize plants (Sessitsch et al. 2012). Proteomic studies have also indicated that $G$. diazotrophicus expressed ROS-detoxifying enzymes (namely, catalase, peroxiredoxin protein, and SOD) during the interaction with sugarcane (Lery et al. 2011). In our report, in addition to reinforcing these observations by qPCR analysis, we confirm the importance of two ROS-detoxifying enzymes, GR and SOD, showing that the absence of these enzymes could alter the profile of ROS accumulation in roots, resulting in an impaired endophytic colonization.

GR is an enzyme that reduces oxidized glutathione (GSSG) to its reduced form (GSH), which is an important cellular antioxidant. Previous work showed that the reduction of the Medicago truncatula GSH pool leads to a large decrease in the number of nascent $S$. meliloti nodules (Frendo et al. 2005) and reduced efficiency in biological nitrogen fixation (El Msehli et al. 2011; Harrison et al. 2005). Our study shows that the control of the ratio of reduced to GSSG is critical for the establishment of a successful endophytic interaction.

SOD is a metalloenzyme that detoxifies superoxide anion, the first highly toxic radical produced in the ROS cascade. The lack of growth impairment in free-living sod::Tn5 bacteria shows that cells do not suffer from excessive oxidative damage before they come into contact with the plant. On the other hand, the impaired colonization ability of the sod::Tn5 mutant is a strong indication that the plant ROS production causes severe damage in the mutant, making it unable to detoxify superoxide anions, which further blocks endophytic plant colonization. Proteomic studies using different bacteria and plant models consistently show the upregulation of bacterial SOD expression in response to plant exudates or when bacteria are living in association with plants (Knief et al. 2011). The effects of the deletion of an SOD gene were also investigated in a previous work using $S$. meliloti-alfalfa as model; it was shown that bacterial SOD is critical for efficient nodulation and nitrogen fixation (Santos et al. 2000). Our similar results in a different system indicate that the protective role of SOD occurs in several bacteria-plant models and may be a universal mechanism that enables bacteria to colonize plants.

Alternatively or additionally, it is also possible that the excess of endogenous superoxide in the sod::Tn5 mutants is solely responsible for damaging functions critical to the associative phenotype. In any case, our results provide evidence that there is an accumulation of ROS in roots after the perception of these endophytic bacteria and, unless counteracted by GR and SOD, a fully successful endophytic association cannot be achieved.

\section{MATERIALS AND METHODS}

Strain, culture media, and growth conditions used.

G. diazotrophicus PAL5 ${ }^{\mathrm{T}}$ (BR 11281 = ATCC49037) was obtained from the Embrapa Agrobiologia Culture Collection, Seropédica, RJ, Brazil and grown in DYGS liquid medium without magnesium (Rodrigues Neto et al. 1986) at $30^{\circ} \mathrm{C}, 175$ $\mathrm{rpm}$. Antibiotics tetracycline $(20 \mu \mathrm{g} / \mathrm{ml})$ or ampicillin $(500$ $\mu \mathrm{g} / \mathrm{ml}$ ) were added when required. G. diazotrophicus PAL5 electrocompetent cells were prepared as described previously 
(Rouws et al. 2008) using liquid DYGS medium. For cloning purposes, electrocompetent Escherichia coli Top10 cells (Invitrogen, Carlsbad, CA, U.S.A.), were cultivated in Luria-Bertani (LB) medium (Sambrook et al. 1989) amended with the selective antibiotics tetracycline $(20 \mu \mathrm{g} / \mathrm{ml})$ or ampicillin $(100$ $\mu \mathrm{g} / \mathrm{ml})$.

\section{Hydroponic rice cultures.}

Rice (Oryza sativa IR-42) seedlings were cultivated basically as described by Hurek and associates (1994). Briefly, seed were peeled, surface sterilized, and germinated on NB plates (Fluka Chemie AG, Buchs, Switzerland) at $30^{\circ} \mathrm{C}$. Three-day-old seedlings of approximately $1 \mathrm{~cm}$ in length without any visible bacterial or fungal contamination were aseptically transferred to glass tubes ( 200 by $30 \mathrm{~mm}$ ) containing $35 \mathrm{~g}$ of glass beads (1.7 by $2.1 \mathrm{~mm}$ ) (Carl Roth, Karlsruhe, Germany) and $15 \mathrm{ml}$ of a modified Hoagland's solution free of nitrogen and carbon $\left(\mathrm{KH}_{2} \mathrm{PO}_{4}\right.$ at $136 \mathrm{mg} /$ liter, $\mathrm{K}_{2} \mathrm{HPO}_{4}$ at $174 \mathrm{mg} / \mathrm{liter}, \mathrm{MgSO}_{4}$ $7 \mathrm{H}_{2} \mathrm{O}$ at $246 \mathrm{mg} / \mathrm{liter}, \mathrm{CaSO}_{4} \cdot 2 \mathrm{H}_{2} \mathrm{O}$ at $172 \mathrm{mg} / \mathrm{liter}, \mathrm{H}_{3} \mathrm{BO}_{3}$ at $2.8 \mathrm{mg} /$ liter, $\mathrm{MnCl}_{2} \cdot 4 \mathrm{H}_{2} \mathrm{O}$ at $1.8 \mathrm{mg} / \mathrm{liter}, \mathrm{ZnSO}_{4} \cdot 7 \mathrm{H}_{2} \mathrm{O}$ at $0.2 \mathrm{mg} /$ liter, $\mathrm{CuSO}_{4} \cdot 5 \mathrm{H}_{2} \mathrm{O}$ at $0.08 \mathrm{mg} / \mathrm{liter}$, and $\mathrm{Na}_{2} \mathrm{MoO}_{4}$ $2 \mathrm{H}_{2} \mathrm{O}$ at $0.02 \mathrm{mg} / \mathrm{liter}$ ). Plants were cultivated in a growth chamber at day and night temperatures of 23 and $18^{\circ} \mathrm{C}$, respectively, with a 12-h photoperiod, with light provided by fluorescent tubes.

For inoculation purposes, $G$ diazotrophicus was grown as previously described, washed with sterile phosphate-buffered saline (PBS) buffer, and diluted to an absorbance at $600 \mathrm{~nm}$ $\left(\mathrm{A}_{600}\right)=1$, corresponding to a concentration of $10^{9}$ cells $/ \mathrm{ml}$ of suspension. Three-day-old axenic seedlings of approximately $1 \mathrm{~cm}$ in length were transferred to $15-\mathrm{ml}$ Falcon tubes containing $3 \mathrm{ml}$ of cell suspension and incubated for $1 \mathrm{~h}$ at room temperature with $100 \mathrm{rpm}$ agitation. Sterile PBS solution buffer was used in control seedlings.

\section{Real-time qPCR.}

qPCR was performed essentially as described by Alquéres and associates (2012), with few modifications. Expression of selected genes were determined by real-time qPCR with Power SYBR Green Supermix (Applied Biosystems, Foster City, CA, U.S.A.) using an iCycler thermal cycler (Applied Biosystems). In all, 8 to 10 plants or seedlings were pooled and total RNA was extracted with TRizol (Invitrogen) from frozen material according to the manufacturer's instructions (for plants). After DNase I treatment, $1 \mu \mathrm{g}$ of RNA was used for cDNA synthesis using the High Capacity cDNA Reverse Transcription Kit with RNase Inhibitor (Applied Biosystems). cDNA dilutions $(1 \mu \mathrm{l}$, 1:4) were used as PCR templates. Each PCR reaction contained $12.5 \mu \mathrm{l}$ of $2 \times$ Power SYBR Green Supermix, $0.4 \mu \mathrm{M}$ primers (Eurofins MVG Operon, Ebersberg, Germany), and $1 \mu \mathrm{l}$ of template in a $25-\mu 1$ reaction. PCR reactions were heated to $95^{\circ} \mathrm{C}$ for $3 \mathrm{~min}$ and then for 40 cycles with steps of $95^{\circ} \mathrm{C}$ for $30 \mathrm{~s}, 60^{\circ} \mathrm{C}$ for $30 \mathrm{~s}$, and $60^{\circ} \mathrm{C}$ for $30 \mathrm{~s}$. The generation of specific PCR products was confirmed by melting curve analysis and gel electrophoresis. The $2^{-\Delta \Delta \mathrm{Ct}}$ method (Livak and Schmittgen 2001) was employed for relative quantification, 23S rRNA was used as the bacterial endogenous control, and ubiquitin was used as the plant endogenous control. The sequences of the primers for bacterial genes are 23SF: AAAG CCGGATCAATCCGTTA, 23SR: AAGCCGTAGTCGATGGA AAC, GDI2168F: CCCGCCCATGCAAT, GDI2168R: AGG GTGGGCAATTCGAAAG，GDI2216F： TGTGTCCCCAAG AAGCTGATG, GDI2216R: GATGTTCCAGCCGAAACCAT, GDI2280F: GAGGCGATGCTGTTTACCC, GDI2280R: TC CCAATAGGACGAAACCTG, GDI79F: GTTCGAAGTCA CCCACGATGT, GDI79R: CCCGGTTGCAGGAATTTG, GDI467F: ACGATATTCCGGTCTTCGTC, GDI467R: CAG GTCGCGAAATTCCTG, GDI2359F: TTCATCGTCGTGACC TTTGG, and GDI2359R: TTCCCATTCCGGAAAATCG. The primers for plant genes were described by Qiu and associates (2007). The quantity of interested genes was normalized to the quantity of the endogenous control for each condition. The experiments were done in biological triplicates (each with two technical replicates). Results were based on the average of triplicates and standard deviation (SD) is shown.

\section{Cloning and mutagenesis of $G$. diazotrophicus.}

The SOD and GR genes were amplified by PCR with specific primers. The 705-bp (for SOD, GDI_2168) and 1,513-bp (for GR, GDI_2216) PCR products were cloned into the pGEM-T vector (Promega Corp., Madison, WI, U.S.A.). After confirming the success of the cloning procedure by PCR and sequencing, one recombinant plasmid containing the desired fragment was selected and mutagenized in vitro by the insertion of the commercial EZ::Tn5<TET>Transposon (Tn5) (Epicentre Technologies Corp., Madison, WI, U.S.A.) following the instructions of the manufacturer. The mutagenized plasmid was transferred to E. coli Top10 (Invitrogen) and plated on LB medium containing ampicillin and tetracycline to select plasmids containing insertions of the transposon in the target gene. Sequence analysis led to the identification of the plasmids with a single insertion of the transposon located 296 bp downstream of the predicted ATG start codon of the SOD gene and $546 \mathrm{bp}$ downstream of the predicted ATG start codon of the GR gene. WT was transformed with $1 \mu \mathrm{g}$ of the plasmid by electroporation as described (Rouws et al. 2008) and selection was done on DYGS plates (without $\mathrm{Mg}_{2} \mathrm{SO}_{4} \cdot 7 \mathrm{H}_{2} \mathrm{O}$ ) amended with tetracycline, allowing the selection of transformants containing
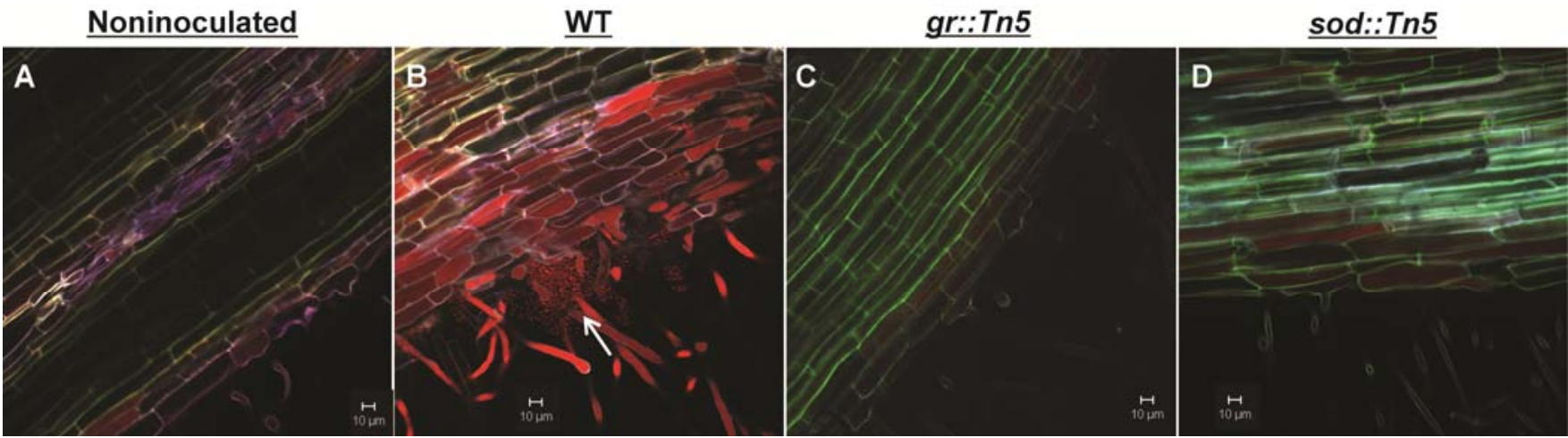

Fig. 6. In situ detection of B, wild-type (WT); C, gr::Tn5; and D, sod::Tn5 by fluorescence in situ hybridization analysis and confocal laser-scanning microscopy in roots and root hairs. A, Noninoculated plants. Gluconacetobacter diazotrophicus is identified by the color red from the probe Glac1430 labeled with Cy3. Arrow indicates bacterial clump. Background autofluorescence signals are assigned with green and blue colors. 
Tn5 integrations in their genomes. A second round of selection on DYGS plates medium containing both tetracycline and ampicillin allowed the selection of one mutant resistant only to tetracycline. This indicates that the backbone of the mutagenic plasmid had been eliminated by the mechanism of double crossing-over, leaving only an insertion of the transposon at the desired site. The insertion of the transposon in the $G$. diazotrophicus genome was verified by PCR followed by sequencing of the product, as previously described (Meneses et al. 2011).

\section{Morphological and physiological studies.}

Growth of the WT and mutants in liquid cultures was monitored by measuring the $\mathrm{A}_{600}$ and CFU. Strains were grown in 250 -ml flasks containing $50 \mathrm{ml}$ of liquid at $30^{\circ} \mathrm{C}$ and $175 \mathrm{rpm}$ in LGI-P medium $\left(\mathrm{K}_{2} \mathrm{HPO}_{4}\right.$ at $0.2 \mathrm{~g} /$ liter, $\mathrm{KH}_{2} \mathrm{PO}_{4}$ at 0.6 g/liter, $\mathrm{MgSO}_{4} \cdot 7 \mathrm{H}_{2} \mathrm{O}$ at $0.2 \mathrm{~g} /$ liter, $\mathrm{CaCl}_{2} \cdot 2 \mathrm{H}_{2} \mathrm{O}$ at 0.02 g/liter, $\mathrm{Na}_{2} \mathrm{MoO}_{4} \cdot 2 \mathrm{H}_{2} \mathrm{O}$ at $0.002 \mathrm{~g} /$ liter, $\mathrm{FeCl}_{3} \bullet 6 \mathrm{H}_{2} \mathrm{O}$ at 0.01 $\mathrm{g} / \mathrm{liter}$, and sucrose at $100 \mathrm{~g} / \mathrm{liter}$ ) (Reis et al. 1994) supplemented with $1.0 \mathrm{mM}$ (nitrogen-fixing condition) or $20 \mathrm{mM}$ (non-nitrogen-fixing condition) $\left(\mathrm{NH}_{4}\right)_{2} \mathrm{SO}_{4}$. Every $12 \mathrm{~h}, 1-\mathrm{ml}$ samples were removed for analysis. For counting, samples were serially diluted in saline $(\mathrm{NaCl} 0.7 \%$ [wt/vol] solution) and 10 $\mu \mathrm{l}$ droplets of each dilution were deposited onto DYGS solid medium. After incubation for 3 days at $30^{\circ} \mathrm{C}$, colonies were counted and $\mathrm{CFU}$ were determined. Pellicle formation was evaluated by growing the indicated strains in $\mathrm{N}$-free semisolid LGI-P medium for 6 days.

To assay ROS sensitivity, $10^{6}$ cells of $G$. diazotrophicus strains were plated on DYGS medium. Filter disks of Whatman paper $(5 \mathrm{~mm})$ were soaked with $5 \mu \mathrm{l}$ of $\mathrm{H}_{2} \mathrm{O}_{2}(35 \%$ [vol/ vol]) or Paraquat $(10 \mathrm{mM})$ and placed on the plates. The halo sizes were measured in triplicate after $48 \mathrm{~h}$ of incubation.

\section{Detection of ROS in rice roots.}

The inoculation procedure of rice roots with WT and mutants was performed as described before. At different times after inoculation, the primary roots were excised, briefly washed with $1 \mathrm{mM}$ Tris- $\mathrm{HCl}(\mathrm{pH} \mathrm{8.0)}$ ), then incubated with 10 $\mu \mathrm{M} \quad 2^{\prime}, 7^{\prime}$-dichlorodihydrofluorescein diacetate (Molecular Probes; Invitrogen) in Tris-HCl buffer for $10 \mathrm{~min}$. Fluorescence developed upon oxidation of the dye by hydrogen peroxide, peroxyl radical, and also peroxynitrite anion (Tarpey and Fridovich 2001). Stock solutions of the dye were prepared in dimethyl sulfoxide and kept in the dark at $-80^{\circ} \mathrm{C}$. Before microscopy, samples were briefly rinsed in Tris buffer to remove the dye that had not penetrated into the tissue. Roots were imaged by a Zeiss microscope using a $\times 5$ Zeiss EC PlanNeofluar and optical filters set to a maximum absorption wavelength of $488 \mathrm{~nm}$ and maximum emission wavelength of $530 \mathrm{~nm}$. Images of optical sections corresponding to the root cortex of the whole length of the root were acquired digitally using an exposure time of $10 \mathrm{~ms}$. Images were analyzed using the program ImageJ to calculate the average fluorescence intensity per root. Results were based on the average of quintuplicates, and standard deviation is shown.

\section{FISH.}

FISH was performed as described by Stoffels and associates (2001). Root samples were fixed and dehydrated by passing them through an ethanol series $(50,80$, and $96 \%$ [vol/vol]) for 5 min each. After being dried, roots were covered with $70 \mu \mathrm{l}$ of hybridization buffer containing $0.9 \mathrm{M} \mathrm{NaCl}, 0.01 \%$ sodium dodecyl sulfate (SDS), $10 \mathrm{mM}$ Tris- $\mathrm{HCl}$ (pH 8.0), 35\% deionized formamide, and $15 \mathrm{pmol}$ of fluorescently labeled probe. Hybridizations were performed for at least $2 \mathrm{~h}$ at $46^{\circ} \mathrm{C}$. After hybridization, the root pieces were transferred into the wash- ing buffer (10 mM Tris-HCl [pH 8.0], 5 mM EDTA [pH 8.0], $70 \mathrm{mM} \mathrm{NaCl}$, and $0.01 \% \mathrm{SDS}$ ) for $20 \mathrm{~min}$ at $48^{\circ} \mathrm{C}$ and dipped in deionized water to remove remaining salts. After air drying, the slides were mounted with Citifluor anti-bleaching agent AF1 (Citifluor Ltd., Canterbury, U.K.) The oligonucleotide probe Glac 1430 (Franke-Whittle et al. 2005) (Eurofins MVG Operon, Ebersberg, Germany), complementary to a region of the 16S-rRNA conserved in the Gluconacetobacter subgroup and labeled at the $5^{\prime}$ end with the fluorescent dye $\mathrm{Cy} 3$, was used (Stoffels et al. 2001).

\section{CLSM.}

CLSM was performed on samples stained by FISH. Visualization was performed using a Zeiss 510LSM-Meta confocal laser-scanning microscope (Zeiss) with helium neon and argon ion lasers for excitation of $\mathrm{Cy} 3$ at $543 \mathrm{~nm}$ and control excitation wavelengths of 488 and $633 \mathrm{~nm}$, both of which excite only autofluorescence. Cells were observed under water immersion using a $\times 40$ objective. In hybridizations using the Cy3-labeled oligonucleotide probe, fluorescent signals were assigned a red color and background autofluorescence signals were assigned green and blue. Images were acquired using a Zeiss LSM Image browser.

\section{Endophytic colonization experiments.}

Endophytic colonization was evaluated as previously described (Rouws et al. 2010). Briefly, $10^{8} \mathrm{CFU}$ of the $G$. diazotrophicus strains suspended in $330 \mu \mathrm{l}$ of saline were added directly into the Hoagland's solution $(15 \mathrm{ml})$ of 7-day-old rice seedlings, which were grown as described above. Control plants were inoculated with $330 \mu$ of saline solution. At 10 dai, the roots were separated from the aerial parts and weighed after draining the adhering liquid onto absorbent paper. The root material was either directly ground in a mortar, diluted, and plated, or surface disinfected by incubation in a freshly prepared chloramine $\mathrm{T}$ solution $(1 \%$ [wt/vol] $)$ for $2 \mathrm{~min}$ under gentle agitation followed by extensive washing with sterile water, then diluted and plated in DYGS medium. The number of CFU was quantified after 3 days of incubation. Intact roots were placed on LGI-P plates for $10 \mathrm{~s}$ to verify the surface sterilization procedure. The experiments were done in biological triplicates (each with a pool of 10 plants and three technical replicates). Results were based on the average of triplicates. Error bars represent the SD.

\section{ACKNOWLEDGMENTS}

The initial phase of this work was supported by the project CNPq/INCT-FBN. We thank A. Weiss for skillful technical assistance; E. K. James and H.-M Fischer for helpful comments and suggestions; and CAPES (Higher Education Coordination Agency, linked to the Ministry of Education, Brazil) for the fellowship.

\section{LITERATURE CITED}

Alquéres, S., Oliveira, J. H., Nogueira, E., Guedes, H., Oliveira, P., Câmara, F., Baldani, I., and Martins, O. 2010. Antioxidant pathways are up-regulated during biological nitrogen fixation to prevent ROSinduced nitrogenase inhibition in Gluconacetobacter diazotrophicus. Arch. Microbiol. 192:835-841.

Alquéres, S., Cardoso, A., Brito-Moreira, J., Baldani, J. I., and Martins, O. 2012. Transfer RNA-dependent asparagine biosynthesis in Gluconacetobacter diazotrophicus and its influence on biological nitrogen fixation. Plant Soil 356:209-216.

Apostol, I., Heinstein, P. F., and Low, P. S. 1989. Rapid stimulation of an oxidative burst during elicitation of cultured plant cells: role in defense and signal transduction. Plant Physiol. 90:109-116.

Baron, C., and Zambryski, P. C. 1995. The plant response in pathogenesis, symbiosis and wounding: variations on common theme? Annu. Rev. Genet. 29:107-129. 
Bertalan, M., Albano, R., De Pádua, V., Rouws, L., Rojas, C., Hemerly, A. Teixeira, K., Schwab, S., Araujo, J., Oliveira, A., França, L., Magalhães, V., Alquéres, S., Cardoso, A., Almeida, W., Loureiro, M.M., Nogueira, E., Cidade, D., Oliveira, D., Simão, T., Macedo, J., Valadão, A., Dreschsel, M., Freitas, F., Vidal, M., Guedes, H., Rodrigues, E., Meneses, C., Brioso, P., Pozzer, L., Figueiredo, D., Montano, H., Jr., J., de Souza Filho, G., Martin Quintana Flores, V., Ferreira, B., Branco, A. T., Gonzalez, P., Guillobel, H., Lemos, M., Seibel, L., Macedo, J., Alves-Ferreira, M., Sachetto-Martins, G., Coelho, A., Santos, E., Amaral, G., Neves, A., Pacheco, A. B., Carvalho, D., Lery, L., Bisch, P., Rössle, S. C., Urményi, T., Rael Pereira, A., Silva, R., Rondinelli, E., von Krüger, W., Martins, O., Baldani, J. I., and Ferreira, P. C. 2009. Complete genome sequence of the sugarcane nitrogen-fixing endophyte Gluconacetobacter diazotrophicus Pal5. BMC Genomics 10:450.

Blanco, Y., Blanch, M., Piñón, D., Legaz, M.-E., and Vicente, C. 2005. Antagonism of Gluconacetobacter diazotrophicus (a sugarcane endosymbiont) against Xanthomonas albilineans (pathogen) studied in alginate-immobilized sugarcane stalk tissues. J. Biosci. Bioeng. 99:366371.

Bordiec, S., Paquis, S., Lacroix, H., Dhondt, S., Ait Barka, E., Kauffmann, S., Jeandet, P., Mazeyrat-Gourbeyre, F., Clément, C., Baillieul, F., and Dorey, S. 2011. Comparative analysis of defence responses induced by the endophytic plant growth-promoting rhizobacterium Burkholderia phytofirmans strain PsJN and the non-host bacterium Pseudomonas syringae pv. pisi in grapevine cell suspensions. J. Exp. Bot. 62:595-603.

Cavalcante, J. J. V, Vargas, C., Nogueira, E. M., Vinagre, F., Schwarcz, K., Baldani, J. I., Ferreira, P. C. G., and Hemerly, A. S. 2007. Members of the ethylene signalling pathway are regulated in sugarcane during the association with nitrogen-fixing endophytic bacteria. J. Exp. Bot. 58:673-686

Cavalcante, V. A., and Dobereiner, J. 1988. A new acid-tolerant nitrogenfixing bacterium associated with sugarcane. Plant Soil 108:23-31.

Doke, N., Miura, Y., Sanchez, L. M., Noritake, T., Yoshioka, H., and Kawakita, K. 1996. The oxidative burst protects plants against pathogen attack: mechanism and role as an emergency signal for plant biodefence. Gene 179:45-51.

Dong, Z., McCully, M. E., and Canny, M. J. 1997. Does Acetobacter diazotrophicus live and move in the xylem of sugarcane stems? Anatomical and physiological data. Ann. Bot. 80:147-158.

El Msehli, S., Lambert, A., Baldacci-Cresp, F., Hopkins, J., Boncompagni, E., Smiti, S. A., Hérouart, D., and Frendo, P. 2011. Crucial role of (homo)glutathione in nitrogen fixation in Medicago truncatula nodules. New Phytol. 192:496-506.

Franke-Whittle, I. H., O’Shea, M. G., Leonard, G. J., and Sly, L. I. 2005. Design, development, and use of molecular primers and probes for the detection of Gluconacetobacter species in the pink sugarcane mealybug. Microb. Ecol. 50:128-139.

Frendo, P., Harrison, J., Norman, C., Hernández Jiménez, M. J., Van de Sype, G., Gilabert, A., and Puppo, A. 2005. Glutathione and homoglutathione play a critical role in the nodulation process of Medicago truncatula. Mol. Plant-Microbe Interact. 18:254-259.

Harrison, J., Jamet, A., Muglia, C. I., Sype, G. Van De, Aguilar, O. M., Puppo, A., and Frendo, P. 2005. Glutathione plays a fundamental role in growth and symbiotic capacity of Sinorhizobium meliloti. J. Bacteriol. 187:168-174.

Hurek, T., Reinhold-Hurek, B., Van Montagu, M., and Kellenberger, E. 1994. Root colonization and systemic spreading of Azoarcus sp. strain BH72 in grasses. J. Bacteriol. 176:1913-1923.

James, E. K., Olivares, F. L., De Oliveira, A. L., Dos Reis, F. B., Jr., Da Silva, L. G., and Reis, V. M. 2001. Further observations on the interaction between sugar cane and Gluconacetobacter diazotrophicus under laboratory and greenhouse conditions. J. Exp. Bot. 52:747-760.

Knief, C., Delmotte, N., and Vorholt, J. 2011. Bacterial adaptation to life in association with plants-a proteomic perspective from culture to in situ conditions. Proteomics 11:3086-3105.

Koornneef, A., Leon-Reyes, A., Ritsema, T., Verhage, A., Den Otter, F. C., Van Loon, L. C., and Pieterse, C. M. J. 2008. Kinetics of salicylatemediated suppression of jasmonate signaling reveal a role for redox modulation. Plant Physiol. 147:1358-1368.

Lamb, C., and Dixon, R. A. 1997. the Oxidative burst in plant disease resistance. Annu. Rev. Plant Physiol. Plant Mol. Biol. 48:251-275.

Lery, L. M. S., Hemerly, A. S., Nogueira, E. M., Von Krüger, W. M., and Bisch, P. M. 2011. Quantitative proteomic analysis of the interaction between the endophytic plant-growth-promoting bacterium Gluconacetobacter diazotrophicus and sugarcane. Mol. Plant-Microbe Interact. 24:562-576

Levine, A., Tenhaken, R., and Lamb, C. 1994. $\mathrm{H}_{2} \mathrm{O}_{2}$ from the oxidative burst orchestrates the plant hypersensitive disease resistance response. Cell 79:583-593.
Livak, K. J., and Schmittgen, T. D. 2001. Analysis of relative gene expression data using real-time quantitative PCR and the 2-[delta][delta]CT method. Methods 25:402-408.

Mehnaz, S., and Lazarovits, G. 2006. Inoculation effects of Pseudomonas putida, Gluconacetobacter azotocaptans, and Azospirillum lipoferum on corn plant growth under greenhouse conditions. Microb. Ecol. 51:326-335.

Meneses, C. H. S. G., Rouws, L. F. M., Simoes-Araujo, J. L., Vidal, M. S., and Baldani, J. I. 2011. Exopolysaccharide production is required for biofilm formation and plant colonization by the nitrogen-fixing endophyte Gluconacetobacter diazotrophicus. Mol. Plant-Microbe Interact. 24:1448-1458.

Miché, L., Battistoni, F., Gemmer, S., Belghazi, M., and Reinhold-Hurek, B. 2006. Upregulation of jasmonate-inducible defense proteins and differential colonization of roots of Oryza sativa cultivars with the endophyte Azoarcus sp. Mol. Plant-Microbe Interact. 19:502-511.

Molina, L., and Kahmann, R. 2007. An Ustilago maydis gene involved in $\mathrm{H}_{2} \mathrm{O}_{2}$ detoxification is required for virulence. Plant Cell 19:22932309.

Muthukumarasamy, R., Cleenwerck, I., Revathi, G., Vadivelu, M., Janssens, D., Hoste, B., Ui Gum, K., Park, K.-D., Young Son, C., Sa, T., and Caballero-Mellado, J. 2005. Natural association of Gluconacetobacter diazotrophicus and diazotrophic Acetobacter peroxydans with wetland rice. Syst. Appl. Microbiol. 28:277-286.

Nogueira, E. D. M., Vinagre, F., Masuda, H. P., Vargas, C., De Pádua, V. L. M., Da Silva, F. R., Dos Santos, R. V., Baldani, J. I., Ferreira, P. C. G. and Hemerly, A. S. 2001. Expression of sugarcane genes induced by inoculation with Gluconacetobacter diazotrophicus and Herbaspirillum rubrisubalbicans. Genet. Mol. Biol. 24:199-206.

Pieterse, C. M. J., Leon-Reyes, A., Van der Ent, S., and Van Wees, S. C. M. 2009. Networking by small-molecule hormones in plant immunity. Nat. Chem. Biol. 5:308-316.

Qiu, D., Xiao, J., Ding, X., Xiong, M., Cai, M., Cao, Y., Li, X., Xu, C., and Wang, S. 2007. OsWRKY13 mediates rice disease resistance by regulating defense-related genes in salicylate- and jasmonate-dependent signaling. Mol. Plant-Microbe Interact. 20:492-499.

Ramu, S. K., Peng, H.-M., and Cook, D. R. 2002. Nod factor induction of reactive oxygen species production is correlated with expression of the early nodulin gene rip1 in Medicago truncatula. Mol. Plant-Microbe Interact. 15:522-528

Reis, V. M., Olivares, F. L., and Döbereiner, J. 1994. Improved methodology for isolation of Acetobacter diazotrophicus and confirmation of its endophytic habitat. World J. Microbiol. Biotechnol. 10:401-405.

Rodrigues Neto, J., Malavolta, V. A., and Junior, V. O. 1986. Meio simples para o isolamento e cultivo de Xanthomonas campestris pv. citri Tipo B. Summa Phytopathol. 12:16.

Rouws, L. F. M., Simões-Araújo, J. L., Hemerly, A. S., and Baldani, J. I. 2008. Validation of a Tn 5 transposon mutagenesis system for Gluconacetobacter diazotrophicus through characterization of a flagellar mutant. Arch. Microbiol. 189:397-405.

Rouws, L. F. M., Meneses, C. H. S. G., Guedes, H. V., Vidal, M. S., Baldani, J. I., and Schwab, S. 2010. Monitoring the colonization of sugarcane and rice plants by the endophytic diazotrophic bacterium Gluconacetobacter diazotrophicus marked with $g f p$ and gusA reporter genes. Lett. Appl. Microbiol. 51:325-330.

Sambrook, J., Fritsch, E. F., and Maniatis, T. 1989. Molecular Cloning: A Laboratory Manual. Cold Spring Harbor Laboratory Press, Cold Spring Harbor, NY, U.S.A.

Santos, R., Hérouart, D., Puppo, A., and Touati, D. 2000. Critical protective role of bacterial superoxide dismutase in rhizobium-legume symbiosis. Mol. Microbiol. 38:750-759.

Santos, R., Hérouart, D., Sigaud, S., Touati, D., and Puppo, A. 2001. Oxidative burst in alfalfa-Sinorhizobium meliloti symbiotic interaction. Mol. Plant-Microbe Interact. 14:86-89.

Saravanan, V. S., Madhaiyan, M., and Thangaraju, M. 2007. Solubilization of zinc compounds by the diazotrophic, plant growth promoting bacterium Gluconacetobacter diazotrophicus. Chemosphere 66:17941798.

Sessitsch, A., Hardoim, P., Döring, J., Weilharter, A., Krause, A., Woyke, T., Mitter, B., Hauberg-Lotte, L., Friedrich, F., Rahalkar, M., Hurek, T. Sarkar, A., Bodrossy, L., Van Overbeek, L., Brar, D., Van Elsas, J. D., and Reinhold-Hurek, B. 2012. Functional characteristics of an endophyte community colonizing rice roots as revealed by metagenomic analysis. Mol. Plant-Microbe Interact. 25:28-36.

Sevilla, M., Burris, R. H., Gunapala, N., and Kennedy, C. 2001. Comparison of benefit to sugarcane plant growth and ${ }^{15} \mathrm{~N}_{2}$ incorporation following inoculation of sterile plants with Acetobacter diazotrophicus wild-type and Nif mutants strains. Mol. Plant-Microbe Interact. 14:358-366. 
Stoffels, M., Castellanos, T., and Hartmann, A. 2001. Design and application of new 16S rRNA-targeted oligonucleotide probes for the Azospirillum-Skermanella-Rhodocista cluster. Syst. Appl. Mircobiol. 24:8397.

Tarpey, M. M., and Fridovich, I. 2001. Methods of detection of vascular reactive species: nitric oxide, superoxide, hydrogen peroxide, and peroxynitrite. Circ. Res. 89:224-236.

Torres, M. A., Jones, J. D. G., and Dangl, J. L. 2006. Reactive oxygen species signaling in response to pathogens. Plant Physiol. 141:373-378.

Van Loon, L., Bakker, P., and Pieterse, C. 1998. Systemic resistance induced by rhizosphere bacteria. Annu. Rev. Phytopathol. 36:453-483.

Van Loon, L. C., Bakker, P. A. H. M., Van der Heijdt, W. H. W., Wendehenne, D., and Pugin, A. 2008. Early responses of tobacco sus- pension cells to rhizobacterial elicitors of induced systemic resistance. Mol. Plant-Microbe Interact. 21:1609-1621.

Van Wees, S. C. M., Van der Ent, S., and Pieterse, C. M. J. 2008. Plant immune responses triggered by beneficial microbes. Curr. Opin. Plant Biol. 11:443-448.

Verhagen, B. W. M., Trotel-Aziz, P., Couderchet, M., Höfte, M., and Aziz, A. 2010. Pseudomonas spp.-induced systemic resistance to Botrytis cinerea is associated with induction and priming of defence responses in grapevine. J. Exp. Bot. 61:249-260.

Wojtaszek, P. 1997. Oxidative burst: an early plant response to pathogen infection. Biochem. J. 322:681-692.

Zamioudis, C., and Pieterse, C. M. J. 2012. Modulation of host immunity by beneficial microbes. Mol. Plant-Microbe Interact. 25:139-150. 